\title{
Foot loading of an African population
}

\author{
Niki M Stolwijk $k^{*}$, Jacques Duysens ${ }^{1,3}$, Jan-Willem K Louwerens², Noel LW Keijsers ${ }^{1}$ \\ From 3rd Congress of the International Foot and Ankle Biomechanics Community \\ Sydney, Australia. 11-13 April 2012
}

\section{Background}

In contrast to western countries, foot complaints are rare in Africa. This is remarkable, as most Africans load their feet significantly more; they walk many hours each day, often barefoot or with worn-out shoes. The reason why Africans can withstand such loading without developing foot complaints might be related to the way the foot is loaded. Therefore, foot shape and dynamic plantar pressure distribution of an African population was compared to a Caucasian population.

\section{Materials and methods}

The plantar pressure distribution of 77 persons from Malawi (Blantyre and surroundings) and 77 Dutch persons were measured using a USB (in Malawi) and 3D (in the Netherlands) Foot Scan ${ }^{\circledR}$ pressure plate (Rsscan Int.). None of the subjects reported foot complaints. The normalized [1] mean pressure (MP), peak pressure (PP) and pressure-time integral (PTI) as well as the Arch Index (AI) and the trajectory of the centre of pressure (COP) during the stance phase were calculated and compared between both groups. Standardized pictures were taken from the feet to assess the medial arch angle.

\section{Results}

The MP, PP and PTI were significantly higher under the midfoot and lower under the heel and metatarsal head II and III for the Malawian group $(\mathrm{p}<0.007)$. Furthermore the AI was significantly higher in the Malawian group (mean 0.28 (SD 0.03) compared to the Dutch group (mean 0.21 (SD 0.06). The COP trajectory was situated more anteriorly during the first and last part of stance and more posteriorly during the middle part of the stance phase. In the Malawi group, the medial arch angle was significantly larger $(\mathrm{p}<0.05)$.

* Correspondence: n.stolwijk@maartenskliniek.nl

'Department of RD\&E, Sint Maartenskliniek, Nijmegen, the Netherlands

Full list of author information is available at the end of the article

\section{Conclusions}

Africans have a different loading pattern compared to Caucasians, with less loading on the forefoot and heel and more contribution of the midfoot and toes during the roll off. This loading pattern generates a more equal distribution of pressure, which might help to prevent for foot complaints.

\section{Author details}

'Department of RD\&E, Sint Maartenskliniek, Nijmegen, the Netherlands. ${ }^{2}$ Orthopaedics, Sint Maartenskliniek, Nijmegen, the Netherlands. ${ }^{3}$ Research Center for Movement Control and Neuroplasticity, Department of Biomedical Kinesiology, Katholieke Universiteit Leuven, Leuven, Belgium.

Published: 10 April 2012

\section{Reference}

1. Keijsers NL, Stolwijk NM, Nienhuis B, Duysens J: A new method to normalize plantar pressure measurements for foot size and progression angle. J Biomech 2009, 42:87-90.

doi:10.1186/1757-1146-5-S1-025

Cite this article as: Stolwijk et al:: Foot loading of an African population. Journal of Foot and Ankle Research 2012 5(Suppl 1):025.

\section{Submit your next manuscript to BioMed Central and take full advantage of: \\ - Convenient online submission \\ - Thorough peer review \\ - No space constraints or color figure charges \\ - Immediate publication on acceptance \\ - Inclusion in PubMed, CAS, Scopus and Google Scholar \\ - Research which is freely available for redistribution

